Mark Jary and Mikhail Kissine*

\title{
When terminology matters: \\ The imperative as a comparative concept
}

\begin{abstract}
The imperative should be thought of as a comparative concept, defined as a sentence type whose only prototypical function is the performance of the whole range of directive speech acts. Furthermore, for a non-second-person form to count as an imperative it must be homogenous with the second-person form, thereby allowing true imperative paradigms to be distinguished from those that recruit alternative structures. This definition of the imperative sentence type allows more accurate crosslinguistic analysis of imperative paradigms, and provides principled grounds for distinguishing between imperative and so-called 'hortative' and 'jussive' forms. It also helps to clarify the irrealis - or better - potential status of imperatives, and suggests an explanation for the crosslinguistic variability in the non-directive occurrence of imperatives in good wishes.
\end{abstract}

Keywords: imperative, subjunctive, irrealis, horative, sentence-type, directive speech acts, potentiality

\section{$1 \quad$ Introduction}

In their introduction to a major typological volume on imperatives, Birjulin and Xrakovski (2001) define imperative sentences as semantically conveying the idea that the speaker informs the hearer that he wishes some action (by a certain agent) to be caused by this very information. Such definitions, which build the imperative's directive function into its semantic core, are not rare (e.g., Hamblin 1987; Barker 2004; Han 2000; for a discussion, see Jary and Kissine 2014: Ch. 4). Now, it is obvious that not all directive speech acts are cast in the imperative. In an appropriate context the declarative in (1), for instance, would make for a perfectly felicitous order that the addressee leave for London the day after.

(1) Tomorrow you are going to London.

Mark Jary: Department of Media, Culture and Language, University of Roehampton, Queen's Building 127 , London SW15 5PU, United Kingdom. E-mail: m.jary@roehampton.ac.uk

Corresponding author: Mikhail Kissine: LaDisco, Université Libre de Bruxelles, CP 175, 50, av. Franklin Roosevelt, 1050 Bruxelles, Belgium. E-mail: mkissine@ulb.ac.be 
Note also that examples like (1) cannot be dismissed as non-literal or indirect (Recanati 1987 : 167; Jary $2010: 72-73$; Kissine 2013 : 111-122). Consider the sarcastic (2) or the indirect (3) speech acts performed with the intent to convey that the addressee should leave for London; in comparison, (1) seems both quite literal and direct.

(2) [Said in a sarcastic tone of voice:] Of course, tomorrow you can stay here and have a lovely day off.

(3) London is a lovely city, you know.

Of cases like (1), Birjulin and Xrakovski (2001: 8) say that these sentences are semantically imperative but 'have the grammatical marking of narrative units'. On most of the current understandings of the semantic-pragmatic interface, however, it would be more plausible to say that (1) is a non-imperative sentence, used as a directive speech act. Importantly, this presupposes that imperative sentences are not exclusively defined in terms of directive force. That is, one needs clear criteria to decide whether a sentence type, independently of the illocutionary function of one of its tokens, is imperative or not. Surprisingly, a satisfying definition of this kind is difficult to find in the literature. ${ }^{1}$ Many authors rely on an intuitive delimitation of the relevant morphosyntactic class; and some simply take for granted the existence of the imperative sentence-type in their attempts to reduce the imperative to a declarative core or define it as a specific semantic type (e.g., Mastop 2005; Portner 2007; Kaufmann 2012). And when one does encounter delineation criteria, as those set out in van der Auwera et al. (2005), their theoretical and methodological justification is left implicit.

In Jary and Kissine (2013) we provide a book-length critical discussion of these, and others theories of the imperative. In this paper we would like to formulate more precisely and defend the definition of the imperative sentence-type suggested in that book. The imperative, we will argue, should be thought of as a comparative concept, in the sense of Haspelmath (2010): it is a crosslinguistic construct that can be functionally defined and employed to compare different, albeit overlapping, categories across languages.

On the account we defend, while the imperative is defined in relation to its prototypical function, the performance of directive speech acts, it does not reduce to it, as will be argued in Section 1. In Section 2, we will show that our point is far from being merely terminological, and that absence of clear definition of what should, and what should not, be described as an imperative impedes the description, let alone the analysis, of fascinating typological differences. In Section 3, we will see that our approach allows one to uncover and explain the

\footnotetext{
${ }^{1}$ For a survey of the history of the notion of mood, see van der Auwera and Aguilar Cordoba (forthcoming).
} 
core that is common to all the manifestations of the imperative across different languages; it helps clarify the irrealis, or better, potential status of imperatives, and provides an explanation for the non-directive occurrence of imperatives in good wishes.

\section{THE DIRECTIVE FUNCTION OF IMPERATIVE MOOD}

A functional definition of the imperative mood may seem straightforward enough: imperative sentences are what we prototypically use to ask or tell other people to act in a certain way, viz. to perform directive speech acts. However, if we are not to cast our net too wide, it is crucial to precisely delineate this functional domain, which will subsequently be used to define the imperative mood as a crosslinguistic comparative concept. We will begin this section by providing a clear definition of directive illocutionary force, that is, of the conditions under which an utterance constitutes a directive speech act. Next, we will restrict the definition of the imperative in such a way so as to rule out non-imperative forms employed to perform indirect speech acts, whether these be conventional or not.

\subsection{Defining directive force}

Commands and orders (4)-(5) are probably the most obvious instances of a directive speech act. $^{2}$ However, it is usually agreed that the category of directive speech acts also includes milder requests, suggestions and pleas (6)-(8), warnings and advice (9)-(10), as well as prohibition and permission (11)-(12).

(4) Stand at attention!

(5) Shut the door.

(6) Put this parcel here, please.

(7) Bring some flowers (if you want to please her).

(8) Don't hurt him!

(9) Watch out for pickpockets!

(10) Read the reviewer's comments carefully.

(11) Don't use my computer in my absence.

(12) Take my car to go to the movies (but be back by ten).

Following Searle (1975a), it has been common to think of directives either as attempts by the speaker to get the hearer to do something, or as expressions of speaker desire, or as

\footnotetext{
${ }^{2}$ While orders and requests are the most prototypical instances of the directive family, this doesn't mean that they are the most common. Politeness considerations may restrict the use of orders and requests, which could go some way to explaining why Van Olmen (2011) found that imperative seem to occur less frequently in orders and requests than in advice or suggestions.
} 
some combination of both. And, according to van der Auwera et al.'s (2005) definition, 'imperatives [...] have to do with the expression of a wish of the speaker about a future state of affairs $[\ldots]$ and convey an appeal to the addressee(s) to help make the future state of affairs true'. While intuitively appealing, such a view of directive force runs into problems when permission and advice are considered, for neither of these can be successfully analysed in such terms: when giving permission or advice, the speaker need not be attempting to get the hearer to perform the act described, nor need she want him to perform that act (e.g., Wilson and Sperber 1988; for an extensive discussion, see Jary and Kissine 2014: 55-65).

One solution to this problem is to maintain a definition of directive force as an expression of the desire and/or the intention that the addressee bring about the truth of the propositional content, and to argue that permission and advice do not belong to the class of genuine directive speech acts. Taken as a purely terminological decision this option is probably as good as any. However, it would force any attempt at a preliminary crosslinguistic characterisation of the imperative to start off with the assumption that in most languages the imperative should be associated with two distinct prototypical functions: 'proper' directive speech acts on the one side and advice, warning and permission on the other. From a typological point of view, it is not wise to split these two families of uses of imperative sentences apart, as the range of uses to which the imperative is put almost always includes advice, warnings and permission.

It is true that one does find in some languages 'preventives', specifically dedicated to warnings, and 'permissives', dedicated to permission (see Golovko 2001 on preventives in Aleut; Gruzdeva 2001 on permissives in Nivkh; Alapatov 2001 on permissives in Japanese). For reasons just seen, advice, warning and permission do seem somehow peripheral directive speech acts, and it is thus not that surprising that some languages should develop highly specific preventive and permissive forms for the performance of a sub-set of directives. However, it is not always clear that these forms genuinely stand in complementary distribution with imperative sentences. In the same vein, even though both permission and warnings can often also be cast in the indicative (e.g., You can take the car or You should watch out for your wallet), we know of no clear evidence of languages where only the indicative, and not the imperative, can be used in permission and warning. To be sure, this kind of relatively subtle question about the use of the imperatives is often difficult to answer solely on the basis of existing descriptions, and more typological work is needed to confirm 
this point. ${ }^{3}$ As things stand today, however, it seems fairly certain that in the vast majority of languages these same functions are happily performed with the imperative. ${ }^{4}$ The existence of specific preventive and permissive forms thus doesn't warrant, in our opinion, definitions of directive force that excludes advice and permission. (Or, at the very least, the burden of the typological proof stays with those willing to defend such definitions.)

To make this last point clearer, compare warnings and permission with good wishes cast in the imperative. There is significant crosslinguistic variation on how productive this last usage is. In English, for example, it shows evidence of being idiomatised: while one can say (13), (14) or (15), example (16) is highly deviant as a good wish.

(13) Have a nice journey back.

(14) Enjoy the show.

(15) Get well soon.

(16) ${ }^{\#}$ Win the lottery.

While some languages (e.g., French and Spanish) exhibit similar preferences to English in this respect, some others may show greater productivity. For instance, while Georgian has an optative mood, specialised for the expression of third-person wishes (with non-stative verbs), for second-person good wishes, the imperative is used instead (Boeder 2010: 626; see also Nasilov et al. 2001 for similar indications on Turkik languages). ${ }^{5}$ By contrast, in Javanese, imperative forms occur only in passive, but while such imperative constructions are used in requests, commands or invitations, good wishes may be performed only with active irrealis verbal forms (Ogloblin 2001). We will return to good wishes below, but for now the point is that while the use of imperatives to express good wishes needs to be accounted for, this

\footnotetext{
${ }^{3}$ To give just one example of the complexity involved, consider the case of Tuyuca, which Aikhenvald (2010: 201) describes as presenting an opposition between imperatives (i) and preventives (apprehensives, in her terminology) (ii):
}

(i) wáa-ya go-IMP 'Go!' naa-ri fall-PREV

'Make sure you don't fall! You might fall (lest you fall)!'

However, in her description Barnes $(1979,92)$ merely speaks of a form which is 'usually more appropriate' than the imperative for giving warnings. Furthermore, in Tuyuaca the suffix -ri expresses negation. In negated imperatives, $-r i$ is followed by the emphasis and the imperative markers; in serial, dependent clauses, however, it can occur in isolation on the verb stem (Barnes 1979; 1994). It is unclear, then, whether (ii) exemplifies a form genuinely different from a negated imperative.

${ }^{4}$ According to Gusev's (2013: 65) estimations, only around 10\% of languages have a specific preventive form.

${ }^{5}$ More precisely, in Georgian, it is the aorist form that is used in directives. This, however, does not change anything to the point that the form prototypically associated with directive speech acts is also used for good wishes, in spite of the existence of a specialised optative mood. 
remains a peripheral use, often realised instead by irrealis or optative forms. In other words, while the preventive and the permissive are forms specialised for the performance of a sub-set of directives, good wishes are speech acts that recruit forms that, crosslinguistically, lie at the intersection between the imperative and the optative/subjunctive type.

It thus makes sense to loosen traditional definitions of directive force to make room for permission, advice and warning, but not good wishes. Here we will favour the account of directives proposed by Kissine (2009; 2013: Ch. 4), according to which directives are illocutionary acts that provide the hearer with a (mutually manifest, in the sense of Sperber and Wilson 1995) reason to act. According to this definition, in a context $C$, an utterance $u$ constitutes a directive speech act with the content $p$ if, and only if, it is mutually manifest in $C$ that $u$ provides the addressee with a reason to bring about the truth of a certain proposition $p$.

Three clarifications are in order here. First, the reasons at hand are not 'explanatory' ones: obviously a directive doesn't amount to a proposition that can be used to explain why the addressee performed or should perform a certain action. Rather, a directive speech act can - but need not - lead the addressee to the decision to bring about the truth of its propositional content. ${ }^{6}$ (Accordingly, a directive with a negated content, such as Don't close the door, provides A with a reason for refraining from performing an action.) Second, an utterance may provide reasons for a number for different actions, some of which may be even unforeseen by the speaker. This is why our definition of directives requires it to be mutually manifest to all parties to the conversation that the utterance at hand provides the addressee with a reason to act. Third, if the directive is direct, its content is explicitly represented by the utterance. We are aware that this way of speaking begs many important issues on the nature of propositions and content, and particularly on that of imperative sentences. For the purposes of this paper, however, we can content ourselves with the intuitive idea that Open the door somehow represents the proposition that the addressee opens the door.

At this point, it should be clear that a directive may express speaker desire, but this is not a necessary condition for an utterance to count as directive. ${ }^{7}$ The reason constituted by a felicitous directive need not be sufficient for acting: a directive speech act can merely be a further reason. This brings permission and advice back within the class of directive speech acts (but keeps good wishes out of it). Another consequence is that invitations (17) and offers

\footnotetext{
${ }^{6}$ Cf. Grice's (2001: 37-44) posthumous typology of reasons; see Kissine (2013: 67-71, 104-105) for a discussion in relation to illocutionary forces.

${ }^{7}$ Kissine's analysis of directive force differs from that of Bach and Harnish (1979) in that his is not couched in terms of the expression and recognition of the speaker's intention that her utterance being taken as a reason to act. For a critique of Bach and Harnish's definition, see Davies (1986: 41) and Jary and Kissine (2014: 57-58).
} 
(18) can be conceived of as directives (which may explain why they are often cast in the imperative): they provide the addressee with a (non-necessarily causally efficient) reason to act, which commits the speaker to a certain course of action should this reason turn efficient.

(17) Pop by this afternoon (if you have time).

(18) Have a beer (if you wish).

At this point, then, we are ready for our first shot at a definition of the imperative as a comparative concept:

IMPERATIVE AS A COMPARATIVE CONCEPT-(ATTEMPT 1):

A sentence-type whose prototypical illocutionary function is to provide the hearer with a reason to act. ${ }^{8}$

\subsection{Indirect speech acts}

Now, of course, the provisional definition just sketched is far too liberal, because many directive speech acts are performed with major non-imperative sentence-types:

(20) You are leaving now.

These morphosyntactic types, though, are associated with other prototypical functions, such as asking questions and making statements. In order to avoid postulating multiple semantic ambiguity for such forms, therefore, one has to restrict the definition of the imperative as a sentence-type whose only prototypical function is to provide the hearer with a reason to act.

However this is still insufficient. Indirect speech acts can famously be 'conventionalised' (Searle 1975b; Morgan 1978; Bach and Harnish 1979; Bach 1998). For instance, constructions such as the Can you_? construction in (21) are so highly conventionalised that authors such as Stefanowitsch (2003) argue that they bear direct association with directive illocutionary force:

Can you close the door?

Such a rationale requires identifying those formal properties of the construction at hand that would put it apart from both imperatives and interrogatives. Like Sadock (1974),

\footnotetext{
${ }^{8}$ The restriction to illocutionary functions is necessary because very often the imperative has also the prototypical function of denoting an action of the addressee (see Section 3.2).
} 
Stefanowitsch (2003) invokes explicit markers of directive force, which, he argues, can occur sentence-internally only in interrogatives used as indirect requests: ${ }^{9}$

Can you please close the door?

Of course, if this criterion is to be used as the ultimate diagnostic of the conventionalisation of some indirect request, then, as shown by the following example from Davies (1986: 21), one runs the risk of an excessive multiplication of 'indirect request constructions':

\section{I'd appreciate it if you would please be quite.}

That said, it remains indisputable that some indirect requests are indeed constituted by deeply conventionalised constructions. According to our provisional definition of the imperative, they should all be considered as imperative sentence-types on their own right - as sentencetypes whose only prototypical function is to perform directive speech acts. Of course, one may bite the terminological bullet and agree that the imperative may, in some languages, cover two very different morphosyntactic templates. But apart from being descriptively inelegant, this option obfuscates many interesting empirical questions relative to potential processing differences between conventional indirect speech acts and imperatives (Ruytenbeek forthcoming), or to diachronic patterns of change, leading from indirect conventional requests forms to bona fide imperatives (Mauri and Sansò 2011). We need, therefore, to identify principled ground for excluding forms used in conventionally indirect directives from our definition of imperatives.

An important point about constructions such as Can you_? is that, despite their conventionality, they can only be used for a limited range of directives. While one can use (21) to perform a request, a command or a supplication, this example can hardly be read as a piece of advice or an act of granting permission - unlike the imperative in (24).

\section{Close the door.}

This suggests that our definition of the imperative should make reference to the fact that this form, unlike others, can be used to perform the full range of directive speech acts. In this way, the following definition of the imperative excludes (conventionally) indirect directives:

\footnotetext{
${ }^{9}$ Sadock's (1974: 97-109) early generative view was the that conventionalised indirect requests and bona fide imperative share a common 'imperative' deep structure (for critical discussions, see Bach and Harnish 1979: 200-202; Levinson 1983: 266; Davies 1986: 21; Jary and Kissine 2014: 16-19)
} 


\section{IMPERATIVE AS A COMPARATIVE CONCEPT-(ATTEMPT 2):}

A sentence-type whose only prototypical illocutionary function is to provide the addressee(s) with a reason to act and that is suitable for the performance of the full range of directive speech acts.

Now, the restriction to the full range of directive helps rule out conventionalised indirect speech acts only if questions are not included within the class of directives. It is true that taxonomies such as Searle and Vanderveken (1985) or Bach and Harnish (1979) conceive of questions as a sub-set of directives: as requests for information, which specifically call for a verbal response. This is very counter-intuitive from a linguistic point of view: while, as will be discussed below, there exist languages with no specific imperative sentence-type, to the best of our knowledge, no language exhibits a full morphosyntactic overlap between interrogatives and imperatives (e.g., Siemund 2001). In addition, Gusev (2013 : 29, 104-7) adduces fascinating typological evidence showing that intonation-wise, imperatives and declaratives pattern together versus interrogatives. Proposals for what interrogative semantics expresses vary from partitioned sets of propositions (answers) to incomplete propositions (e.g., Groenendijk and Stokhof 1989; Fiengo 2007), but, again, one never finds an overlap with what has been suggested as the semantics of imperatives. Of course, this kind of response from our part may seem circular, as it takes for granted an existing delineation of sentence-types. However, even when considered solely as kinds of speech actions, directives and questions are also conceptually very different. An appropriate response to a question has to belong to the assertion family: responding to a question commits one either to some answer or to ignorance. ${ }^{10}$ Directives, by contrast, are responded to either by signalling compliance or by a refusal to comply. On this account, Tell me your name is a directive because one can respond No, whereas What's your name? is a question because it requires an answer. ${ }^{11}$

\section{$2 \quad$ WHY DOES IT MATTER?}

At this stage, some readers might dismiss our definition as trivial. Aren't we just providing a redundant description of forms that appear in direct directive speech acts? What is the benefit of such a definition for the linguist? In this section, we hope to persuade the sceptical reader that, for accurate crosslinguistic description, it is crucial to be clear about what is meant by 'imperative'. We will begin by arguing that something like our definition of the imperative is

\footnotetext{
${ }^{10}$ One may even go as far as claiming that directives can be conceptualised independently of assertion (with some caveats), but questions can't (cf. Levinson, 2012).

${ }^{11}$ Granted, one can also refuse to answer a question, but this is to opt out of the 'language game' initiated by the questioner.
} 
required in order to compare imperative flexional paradigms across languages in a fruitful manner. This will bring us to the delicate issue of languages that seem to have no imperative at all. We will argue that our definition of the imperative allows one to carefully distinguish between markers (of a certain sub-type) of directive force and grammaticalized markers of the imperative mood.

\subsection{Distinctions in flexional paradigms}

It is well-known that morphological imperative paradigms may extend to third, first plural and, more rarely, to the first-person singular (van der Auwera, Dobrushina, and Goussev 2005; Aikhenvald 2010: 76). To quote one particularly striking case, in Nivkh (an isolate spoken around the low reaches of Amur river and on Sakhalin Island) verbs display no person agreement in declarative sentences; in the imperative, however, agreement is compulsory for all the persons, making the case for a full imperative paradigm very persuasive (Gruzdeva 2001). In such a case, the addressee of a directive speech act (viz. the person for whom the utterance is a reason to act) need not coincide with the addressee of the utterance.

Now, deciding how extensive a given imperative paradigm is presupposes that one has an operational crosslinguistic definition of the imperative mood. Let us illustrate this with a consideration of what is sometimes dubbed the 'subjunctive strategy', viz. the widespread tendency to use subjunctive forms to fill the missing cells of imperative paradigms and/or to perform directive speech acts (cf. van der Auwera and Lejeune 2005).

Armenian has morphological imperative second-person singular and plural forms, marked by dedicated suffixation of infinitive or aorist stems. However, when the requested action is to be performed by a group including the speaker, Armenian makes recourse to the first-person plural (present) subjunctive form. Note that this not the only use to which firstperson subjunctive can be put in matrix clauses: it can also be used for expressing wishes or describing an action that will be performed immediately after the utterance time (Kozintseva 2001; Dum-Tragut 2009 : 239-240).

One common descriptive strategy is simply calling any form dedicated to non-secondperson directives 'hortative' or 'jussive' (van der Auwera et al. 2005) or 'non-canonical imperative' (Aikhenvald 2010). However, such uniform labels occlude important crosslinguistic differences. Like Armenian, French has a dedicated second-person (singular and plural) imperative, marked by the bare use of the indicative or subjunctive form. Apart from the compulsory absence of an overt subject, a crucial difference between imperatives on 
the one hand, and indicatives and subjunctives on the other, is that while clitics precede the verb in indicative and subjunctive constructions, they come after the imperative forms:

Que tu $\quad$ le sois...

that you-SG it=be-SBJV.PR.2SG

'That you be it...'

(26) Sois-le

be-IMPV.2SG=it

'Be it.'

The important point here is that, in contrast to Armenian, prototypical first-person plural directive speech acts are, in French, formally similar to the second-person imperatives. Unlike the subjunctive or indicative constructions, imperative forms are characterised by the obligatory omission of the syntactic subject, and by post-verbal clitic position.

(27) Que nous le soyons...

that we it=be-SBJV.PR.1PL...

'That we be this...'

(28) Nous le faisons.

we $\quad$ it $=$ do-IND.PR.1PL

'We do it'

(29) Soyons-le.

be-IMPV.1PL=it

'Let's be it.'

(30) Faisons-le.

do-IMPV.1PL=it

'Let's do it.'

That first-person forms in (29)-(30) really belong to the imperative paradigm is confirmed by the fact that they are unacceptable with a (non-vocative) syntactic subject and with proclitics.

(31) *Nous faisons-le. 
we do-IMPV.1PL=it

*Le faisons.

it=do-IMPV.1PL

There is, then, an essential and interesting typological difference between Armenian and French that would be lost were both languages simply said to have a hortative or 'noncanonical' imperative form. By contrast, given our definition of the imperative mood, it follows that French has first-person-plural imperative, while in Armenian there is no dedicated imperative form, the missing slots of the imperative paradigm being filled by the subjunctive. (Otherwise, one should admit either that some subjunctive forms are also imperative, muddling the definition of forms, or that some subjunctive forms may be used with an imperative function, thereby confusing imperative sentence-type with directive force.)

In addition, we would like to urge an even subtler distinction between non-secondperson imperatives and horatives/jussives, which builds on van der Auwera et al.'s (2005) distinction between minimal and maximal imperative-hortative systems. To this end, let us briefly recall some well-known facts about English let us constructions. Intuitively, (33), as uttered, for instance, by the captain to his football team, is a directive speech act, addressed at a group that includes the speaker.

\section{(33) Let us play a fair game tonight (mates).}

It makes little sense to interpret (33) as a second-person imperative with the verb let, that is, as being equivalent to (34).

\section{Allow us to play a fair game tonight.}

Furthermore, the let us construction used as a form dedicated to the performance of firstperson-plural directive speech acts has salient structural properties. Unlike the second-person imperative with let, it allows first-person tags (35), the contraction of us (36) and internal negation (37) (see Huddleston and Pullum 2002: 935; Jary and Kissine 2014: 35-41):

(35) a. Let us see what you bought, will you? / *Let us see what you bought, shall we? $=$ 'Allow us to see what you bought'

b. $\quad$ *Let us play a fair game tonight, will you? / Let us play a fair game tonight, shall we $\neq$ 'Allow us to play a fair game tonight' 
a. Let us see what you bought

$=$ 'Allow us to see what you bought'

b. Let's see what you bought

$\neq$ 'Allow us to see what you bought'

(37) a. Don't let us leave now

$=$ 'Don't allow us to leave now'

$=$ 'Don't let's leave now

b. Let's not leave

$\neq$ 'Don't allow us to leave now'

$=$ 'Don't let's leave now'

It is then fair to say that English has a form dedicated for the performance of first-person directives. However this specific form is very different from the second-person imperative; in that respect, English differs from, for instance, French, whose first-person plural imperative clearly forms a homogenous paradigm with second-person imperatives.

From a typological point of view, it is important to capture the differences between languages that have no specific form for the performance of 'non-second person' directives, addressed at someone else than the utterance addressee(s) (e.g., Armenian), those where the imperative paradigm include non-second person imperative forms (e.g., French) and those that do display specific forms dedicated to the performance of non-second person directive but where these forms differ from second person imperatives (e.g., English). To this end, we suggest that the term imperative be reserved for forms homogenous with the second-person imperative. (We assume here something like Aikhenvald's (2010: 76) implicational scale, according to which the existence of non-second-person singular imperative forms in a language obligatory implies that this language also a has second-person singular imperative form.)

\section{IMPERATIVE AS A COMPARATIVE CONCEPT-(FINAL):}

A sentence-type whose only prototypical illocutionary function is to provide the addressee(s) with a reason to act, that is suitable for the performance of the full range of directive speech acts, and whose manifestations are all morphologically and syntactically homogenous with the second person.

Terms like hortative should then be reserved for forms that are not morphologically and syntactically homogenous with the second-person imperative but that otherwise fall under our 
definition of the imperative, like the English let us construction. According to our terminology, then, French has a first-person plural imperative, English has a first-person plural hortative and Armenian has no dedicated form for first-person plural directive speech acts.

\subsection{Languages without an imperative}

Without any doubt, the functional category of directive speech acts is instantiated by speakers of every language. However, our definition of the imperative as a comparative concept leaves open the possibility that certain languages are 'imperativeless': these are languages that lack altogether forms whose sole prototypical function is to provide the addressee(s) with a reason to act. We will argue now that far from being an undesirable consequence of our definition, it in fact affords a clearer view on the distinction between imperative forms and directive functions.

It is perhaps timely to expand a little on what should be meant by form here. Clearly, the imperative cannot restricted to verbal moods, because that would deprive, in a rather uninteresting sense, all morphologically poor (or fully isolating) languages from this descriptive category. Rather, the imperative should be thought a sentence-type, in Sadock and Zwicky's (1985) classic sense of a unique mapping between a function and a set of morphosyntactic properties. For instance, in the Amazonian language Canela-Krahô neither tense nor the imperative mood are morphologically marked, but the omission of the syntactic subject is prototypically associated with, and can only occur with, directive force. Thus while the translation of (38) is 'You cut/are cutting the wood', (38) can only be glossed as 'Kill the deer' (Popjes and Popjes 1986).

\begin{tabular}{|c|c|c|}
\hline (38) & $c a$ & jitep \\
\hline & $2 \mathrm{SG}$ & wood cut \\
\hline (39) & po & cura \\
\hline & deer & kill \\
\hline
\end{tabular}

Therefore, even though Canela-Krahô has no imperative morphology proper, the fact that it has a distinct form devoted to directive speech acts warrants the claim that there exists a sentential imperative mood in this language. The same point applies to languages that use another verbal mood in directives. In Hungarian, the imperative affix $-j$ is formally indistinguishable from the subjunctive form (Kenesei et al. 1998). However, since this 'subjunctive' form is only used matrix clauses for the second person with a directive function, 
Hungarian can be said to have an imperative sentence-type after all, ${ }^{12}$ the same applies to Hausa (cf. Dobronravin and Smirnova 2001).

Iberian Spanish provides an interesting case for comparison. Here we find two imperative paradigms, neither of which contains a third-person form. Functionally, the paradigms are distinguished in terms of formality, and each contains both a singular and a plural secondperson form.

(40) Hazlo

do-IMPV.2SG=it (informal)

(41) Hacedlo

do-IMPV.2PL=it (informal)

(42) Hágalo

do-IMPV.2SG=it (formal)

(43) Háganlo

do-IMPV.2PL=it (formal)

There is also a first-person plural form that patterns like a formal form (in that the verb is morphologically identical with the subjunctive) but has no formal connotations, and is best seen as neutral in terms of formality:

(44) Hagámoslo

do-IMPV.1PL=it

While the formal imperatives have the same morphological verb form as the subjunctive, the verb-final cliticisation patterns that they display are found only in imperatives. When a subjunctive is used to perform a directive, by contrast, it must be preceded by the complementizer que and clitics precede the verb:

(45) Que lo hagas

that $\quad \mathrm{it}=\mathrm{do}-\mathrm{SBJV} .2 \mathrm{SG}$

Third-person directives must be performed using the subjunctive construction:

(46) Que lo haga

\footnotetext{
${ }^{12}$ In fact, an imperative paradigm that extends to all persons according to our criteria (cf. de Groot 2014).
} 


\section{that $\quad i t=d o-S B J V .3 S G$}

The second-person subjunctive in Spanish differs from that of Hungarian in that the Spanish construction has non-directive uses: it can be used to express good wishes, for example, in a much more productive way than the imperative can. Furthermore, the subjunctive form is often be used to report the desires of a third-person. This range of uses means that a case such as (45) does not count as an imperative on our account.

German exhibits a similar pattern to Spanish in that the verb in the polite second-person imperative has subjunctive morphology (47), as does the verb in the first-person plural (48). As in Spanish, however, these sentence types should count as imperative because they the exhibit the word-order features of second-person informal imperatives, both singular and plural: any overt subject occurs after the verb (49). This is in contrast to (somewhat archaic) directive uses of the subjunctive in instructions, for example, where the subject precedes the verb (50). Thus the definition proposed in this paper provides principled grounds for distinguishing sentence types as imperative even if the verbal mood is aptly described as subjunctive. $^{13}$

Gehen

go-SUBJ.3PL

Gehen

go-SUBJ.3PL

Geh

go-IMP.2SG

Man nehme

One take-SUBJ.3SG
Sie

you

wir

we

$D u$

you mal vor

already time ahead

schon

already

schon

already

ahead eine Tablette

one tablet

Acknowledging that there are languages that recruit morphological markings used in other functions to build up imperative sentence-types allows interesting comparisons with languages that simply use the same form for several functions including the directive one. ${ }^{14}$ One famous example of the latter kind is the Australisian language Nunggubuyu where directives and assertions about are indistinguishable out of context. That is, the following

\footnotetext{
${ }^{13}$ Thanks to Eva Eppler for help with this German data, and for pointing out that the verb form in (47) and (48) might be labelled otherwise (e.g., infinitive) due to syncretism.

${ }^{14}$ In order, for instance, to trace successive steps in diachronic paths of grammaticalization (cf. Mauri and Sansò 2011)
} 
example can be translated either as the assertion 'You sit down' or the order 'Sit down' (Heath 1984; Verstraete 2005).

ba $=$ bura: $-\hat{v}$

2SG.IRR=sit-NON-PAST

Likewise, Mauri and Sansò (2011) discuss Önge, where assertions about the future and directives are formally indistinguishable and Laz, where the same form is ambiguous between past perfective and directive interpretations. While there is much to say about the functional reasons that render this or that form suitable for being used in directives (Birjulin and Xrakovski 2001; Aikhenvald 2010: 38-47; Mauri and Sansò 2011), our point here is that such theorising (implicitly) presupposes a distinction between languages with and without imperative. Compare our view with Birjulin \& Xrakovski's, for whom verbal forms that belong to the imperative paradigm: '(a) must be regularly built from lexemes whose semantics admits the formation of imperative verb forms, and (b) must be recognizable within the sentence as units with imperative meaning' $(2001,9)$. This definition entails that both Hungarian subjunctives and Nunggubuyu irrealis non-past should count as imperatives. Our definition, by contrast, makes it clear that Hungarian has a dedicated imperative sentencetype, while Nunggubuyu does not.

As an interesting application of the idea that some languages are devoid of an imperative sentential type altogether, consider Vietnamese. Vietnamese is an isolating language and imperative mood is sometimes said to be marked by particles such as $d i$, 'to go' (Bystrov and Stankevič 2001).

(52) ho nĩa $\underline{\tilde{d i}}$
study further

Now, it is a well-known tendency in languages of the world to grammaticalise second-person forms of the verb go as imperative markers (Aikhenvald 2010; Mauri and Sansò 2011). However, according to Bystrov and Stankevič (2001: 466) in Vientamese the di particle occurs only in informal speech; in other contexts a directive speech act can be structurally indistinguishable from an assertion (Đình-Hoà 1997: 158-159). For instance, (53) can be glossed as 'You will carry this bag', 'You carried this bag' or 'Carry this bag'.

anh xách cái túi này
you carry CLASS bag this


Because it cannot cover the full range of directive speech acts, the particle $d i$ does not qualify as a full-fledged imperative marker. It plays the same role as, say, the collocation vas-y ('go ahead'...), in informal French: it emphasises that the utterance is a command or a request, but by no means is it a compulsory element of prototypical directive speech acts.

donne-moi $\quad$ le pain
go.IMP.2SG=there give.IMP.2SG=me the bread
'Come on, give me the bread!'

One may speculate that Vietnamese is at an intermediate diachronic stage where markers of the illocutionary force start to be used in a systematic fashion, but are not yet fully grammaticalised. Such speculation, however, is possible only if one can happily live with the idea that, as yet, there is no imperative in Vietnamese. ${ }^{15}$

\section{WHAT ARE THE PROPERTIES OF IMPERATIVES?}

By definition, a comparative concept may cover different linguistic realities different descriptive concepts — from language to language. However, there must be a semantic-pragmatic core to this concept, determined by its functional value. For instance, Van de Velde (2009) argues convincingly that while proper name, qua a comparative concept, entails direct reference (in the sense of Kripke 1980) to a (salient) entity, other properties, such as specific of patterns of agreement, or of co-occurrence with determiners, are language specific. We have defined the imperative, qua a comparative concept, as a form whose sole prototypical use is the performance of the full range of directive speech acts. The question we would like to address in this section is: Which features make a form specifically suited for this prototypical function? We will begin by arguing that imperatives are inherently potential. Next, we consider the point that, when used with their prototypical illocutionary function, imperatives denote dynamic situations; we will show, however, that there is evidence that this constraint is not an inherent semantic feature of the imperative sentence type qua crosslinguistic category, as there is evidence of variation across languages.

\footnotetext{
${ }^{15}$ The existence of languages without a specific imperative sentence-type poses a great challenge to theories that link, in one way or another, imperative mood with directive force, and are therefore compelled to argue that nonimperative directive speech acts are indirect (Kissine 2012; Kissine 2013: 112-118; see Jary and Kissine 2014: 72-76 for an in-depth discussion of such theories).
} 


\subsection{Potentiality}

Imperative forms are often said to stand on the irrealis side of the realis/irrealis divide. For example, in a highly influential proposal Han (2000) assigns to the imperative [+irrealis] and [+directive] features. The first empirical complication for such claims is that there are languages that combine imperatives with realis markers (e.g., Aikhenvald 2010: 81; Mauri and Sansò 2012). Furthermore, while irrealis forms are often used to supply inexistent imperative forms (Nunggubuyu and Hungarian, discussed above are a case in point), there are also languages that recruit realis forms (as, for instance, Rapanui, which uses realis future marking; see Du Feu 1996: 36-38). The situation is further complicated by the fact that the reality covered by term 'irrealis' is largely inconsistent across different linguistic descriptions (Bybee et al. 1994: 236-240; Elliott 2000; De Haan 2011). We will now argue that the core meaning of imperatives as denoting non-actual states of affairs is better explained in terms of a potentiality constraint.

The fact that a form has a prototypical function does not preclude it from being used for some other function. For example, the declarative mood plausibly has the prototypical function of making statements, but it can also be used to issue directives. As has been noted by Recanati (1987: 163-169), sentences (55) and (56) could be uttered either as statements of fact or, under the right circumstances, as commands. ${ }^{16}$

\section{Tonight I will sleep in a four-poster bed.}

\section{You will clean the latrines.}

What is notable about the imperative, by contrast, is that, at least in independent-clause uses, it is restricted to its prototypical function of issuing directives (we ignore, for the moment, the case of good wishes). Most crucially, the imperative cannot be used to assert the utterance's literal content.

The clearest indication of the fact that imperatives are not suited for the performance of assertion — nor, for that matter, of any speech act of the 'assertive' family — is that they cannot be judged true or false.

\footnotetext{
${ }^{16}$ There is good reason to hold that, when uttered as directives, (55) and (56) are not indirect speech acts (see Introduction). The speaker is not making a claim and thereby ordering: he is simply ordering. This point is supported by the fact that there is no response to either utterance that both accepts it as an order and treats it as an assertion: responding to either with 'That's true' or 'I agree', for example, amounts to failing to recognise the directive intent behind the utterance.
} 
S: Clean the latrines. - A: "Yes, that's true, I will.

(58) S: Clean the latrines. - A: "No, that's not truel that's false, I will never do such a thing.

The imperative's lack of assertoric force potential presents a particular problem for accounts such as Kaufmann (2012), which try to reduce the imperative to a declarative: complex - and ultimately problematic - presuppositional mechanisms must be postulated in order to account for the fact that imperatives cannot be felicitously judged true or false (for a detailed discussion of Kaufmann's theory and her attempt to explain away the imperative's resistance to truth-judgments, see Jary and Kissine 2014: 225-246; Jary and Kissine in press).

But while imperatives cannot be used to make truth-claims, their prototypical function entails that their use is constrained by what is taken to be true at the time of utterance. A felicitous directive is one which can be complied with. This entails that the propositional content of the directive must be neither true at the time of utterance, nor ruled out by what is taken to be common ground at the time of utterance. Thus it is infelicitous both to order a seated person to sit down and to order a completely bald man to comb his hair. In other words, for a directive to be felicitous, the propositional content expressed by the utterance must be potential, where this is understood as being neither part of, nor ruled out by, the common ground. ${ }^{17}$

The question this raises in relation to current concerns is whether potentiality should be seen as a consequence of the prototypical illocutionary function of the imperative or as a semantic feature of the imperative sentence type (understood as a crosslinguistic typological category) that makes it apt for this function. This question can be answered by considering, first, whether there are any non-directive uses of the imperative, and then, if there are, whether these are also subject to the potentiality constraint. If we find uses meeting both conditions, then we have a strong case for holding that potentiality is a semantic feature of the imperative sentence type that specifies it for directive illocutionary acts.

We already find some support for the view that potentiality is a semantic feature of imperative sentences from the above-mentioned observation that they cannot be used to assert the literal content of the utterance. Further support comes from certain non-directive uses that

\footnotetext{
${ }^{17}$ The notion of potentiality has been employed by other authors in the analysis of imperatives, most notably Davies (1986: 48) and Wilson and Sperber (1988). Our account differs from Davies's in that we specify potentiality in relation to the common ground. As regards Wilson and Sperber's proposal, the way the notion of potentiality is presented incorrectly allows for the possibility of using imperatives with assertoric force (for a detailed discussion, see Jary 2011: 270).
} 
imperatives can have in some languages. The most prominent examples here are independentclause imperatives found in good wishes we mentioned earlier. Other uses of imperatives that might be described as non-directive are audienceless cases such as (59).

Please be out. [spoken by a child sent to apologise to neighbours]

(Wilson and Sperber 1988)

Note that both good wishes and audienceless cases retain the potentiality constraint. It would be infelicitous to use (60), say to express one's regret that the hearer had a very bad outward journey, or to use (59) if it is clear to the speaker that the neighbours are at home.

Have a nice journey back.

And while one might utter (61) if one's partner came back car-less with a sorry look, the same utterance would be infelicitous in front of the wrecked car (unless the speaker is taken to convey that she can't believe what's in front of her eyes).

\section{Oh no! Don't have crashed the car again!}

Therefore, we hold that potentiality is a semantic feature of imperatives, independent of their illocutionary force. Furthermore, the fact that in audienceless cases like (59) are subject to the potentiality constraint suggests that potentiality should not be defined relative only to the conversational background, but relative to some relevant body of information (which will most often be the conversational background). In this connection, Dominicy and Franken (2002) observe that the following imperative may be uttered by an archaeologist, who is about to unwrap a mummy, and for whose theory the date of birth of the mummified king is crucial.

\section{Please, be born before 4000 BC!}

The reason (62) is felicitous is that, as far as the relevant background is concerned (the information the archaeologist and his audience have at the utterance time), it is unknown whether or not the mummified king was born before $4000 \mathrm{BC}$ (even though, it is, of course, objectively settled). This why the same utterance would be infelicitous once the mummy has been properly dated.

Further support for the view that potentiality is a semantic feature of imperative sentences can be found in the analysis of their non-main clause uses. ${ }^{18}$ Examination of such

\footnotetext{
${ }^{18}$ Note that because our definition makes reference to illocutionary functions, it does not preclude imperative forms from occurring in non-main clause positions without directive force. This allows us to stay comfortably away from the debate on the (non)-embeddability of imperatives (for claims that imperative don't embed, see, for instance, Han 2000: 119-121 and Maier 2010; for an opposite opinion, see Crnič and Trinh, 2009, Kaufmann 2012: 199-204 and Zanuttini, Pak, and Portner 2012; for a discussion, see Jary and Kissine 2014: 104-108)
} 
cases suggests that the potentiality constraint is still in place, albeit relaxed so that the proposition expressed does not have to be potential relative to the conversational background, as is the case in independent-clause uses, but may instead be potential given a contextual salient set of assumptions.

One non-main-clause use are 'conditional-like imperative' constructions such as the following.

(63) Make any trouble and you got the sack.

(64) Take a holiday in those days and you were considered a spendthrift.

(65) Turn up yesterday and you'd have got a real shock.

(Davies 1986: 165)

In these cases, it can be claimed that the proposition expressed by the imperative clause is potential in relation to some historic information state. It may also be that such uses derive from similar constructions, where the state of affairs described by the imperative is clearly a potential one:

(66) Win the lottery and you won't have to work for the rest of your days.

A number of authors (e.g., Clark, 1993, Han, 2000, Russell, 2007) have disputed the claim that some or all 'conditional-like imperative' constructions contain imperatives, spurred on by the fact that verbal forms in English imperatives are not morphologically marked as such, thus opening the possibility that what appear to be imperatives are, say, infinitives. We side with Davies (1986, see also Iatridou, 2009, von Fintel and Iatridou, 2012) in holding that the first clause in these examples is an imperative, regardless of whether directive force is conveyed or not, and have argued for this position in detail in Jary and Kissine (2013: 114-147). Here, it suffices to say that there are other languages where morphologically unambiguous imperatives have counterfactual meanings in conditional construction, as in the following Russian example: 19

\footnotetext{
${ }^{19}$ Note that the Russian second-person-singular imperative form may combine, in such an environment, with subjects of any persons, which may suggest an on-going semantic change.

(i) Pishi

(by) uchenik,

wirte-IMP.2SG

(COND)pupil

unchitel' ne

delal

by

teacher

NEG

do.PAST.3SG

COND

emu

zamechanij.

to.him

remarks
} 
Pridi ti vchera, vse

come-IMP.2SG you yesterday all

bilo by horocho.

be-PAST.NEUT.SG COND all-right

'If you had come yesterday, all would have been all right."

(Aikhenvald 2010: 237)

\subsection{Agentive interpretation}

In the previous section we argued that the defining the imperative as having the prototypical function of performing directive speech acts implied that imperatives would be apt for describing potential states of affairs. We then considered whether there were grounds for holding that potentiality is a semantic feature of imperative sentences, and found that there were was indeed reason to think so. The prototypical directive function of imperatives also suggests a close affinity with agency, for directives give the hearer reason to act. We might therefore ask the same question in relation to agency: is agency an encoded feature of imperatives that makes these apt for directive use, or does the prototypical function of imperatives merely lead to a close association between agency and the imperative?

At first blush, it might seem that we have strong grounds for holding that agency is a semantic feature of the imperative sentence type. When a stative verb is used in an imperative, the interpretation is generally coerced into a dynamic, agentive reading. Consequently, (68) is interpreted as meaning something like (69). Furthermore, (70) is infelicitous because, although an event predicate, winning a lottery is not under the addressee's control.

(68) Know the answer.

(69) Make sure you know the answer.

(70) ${ }^{\#}$ in the lottery.

Should we claim, therefore, that agency is a semantic feature of imperative sentences, rather than a consequence of their prototypical directive function? In contrast with the case of

'If the pupil had been writing, the teacher would not be making remarks to him.'

from Aikhenvald 2010, 237 
potentiality, there are reasons to think not. First, the agency restriction does not apply to nonindependent-clause imperatives - as evidenced by the contrast between (70) and (71). ${ }^{20}$

Win the lottery and you'll never have to work again

Second, the fact that imperatives can be used to express good wishes (albeit with varying degrees of productivity across languages) argues against positing agency as a semantic feature of the imperative sentence type. Now, some scholars, such as Han (2000: 169), have attempted to explain imperative good wishes away as indirect speech acts, viz. as indirect uses of the imperative, which otherwise is dedicated to the directive force. But this will not do. A crucial property of indirect speech acts is that the direct speech act can at least be recovered. While (72) is an indirect way to ask the addressee to provide Mary's phone number, the primary, direct question about his memory is still available. This is demonstrated by the pragmatic acceptability of the addressee's answering the question and complying with the request at the same time (compare with (73)).

(72) S: Can you remember Mary's phone number?

A: Yes, I can. It is 34464646464.

(73) S: Tell me Mary's phone number!

A: $\quad{ }^{*}$ Yes, I can/I will.

However, it is impossible to come up with an interpretation for, say, (60) where it counts both as a directive and a good wish.

\section{(60) Have a nice journey back. [repeated]}

A prerequisite for the directive interpretation of an utterance is that the addressee has control over the actualization of its content. However strained, one can imagine a context where it actually depends on the addressee of (60) whether he will have a nice journey back - say he will not bother his fellow travellers on the train. But the point is that as soon as one comes up with such a context and reads (60) as a request, the good wish reading is blocked. It thus seems fair to conclude that good wishes, in some languages at least (see Section 1), are genuinely direct and proper uses of imperative sentences.

We cannot, therefore, make the strong claim that agency is a semantic feature of the imperative sentence type, understood as a crosslinguistic typological category. Nevertheless,

\footnotetext{
${ }^{20}$ Recall that in English the felicity of (70) cannot be restored by interpreting it as a good wish.
} 
given the variations in the productivity of this use across languages, a reasonable conjecture is that languages may differ in how strong the constraint on the kind of situation denoted by the imperative is. In languages where imperatives may be used in good wishes, this constraint seems weaker. But because the felicity of good wishes relies on potentiality just as much as the felicity of directives, imperatives are ideal candidates for this function, as long as they can be relieved of the agency constraint.

\section{Conclusion}

In this paper, we have urged a clear-cut definition of morphosyntactic patterns that should be termed, across different linguistic descriptions, as belonging to the imperative sentence-type. The imperative, as a comparative concept, is a sentence-type whose only prototypical illocutionary function is the performance of directive speech acts, and which is suitable for the performance of the full range of directives. We also proposed that the imperative should be reserved only for forms that are homogenous with the second-person imperative: specific sentence types used for the performance of non-second-person singular directives should be called hortatives. We hope to have convinced the reader that our argument is not terminological nagging; without careful categorical delineation, important crosslinguistic differences between imperative paradigms would be blurred.

As far as the semantics of this sentence type goes, we have argued that potentiality is the only feature that is likely to be universal. Agency, though closely related to the illocutionary function of the imperative, is likely to be a semantic feature of some, though not all, instantiations of this sentence type.

Acknowledgments: We are grateful to two anonymous referees for a very constructive feedback on a previous version of this paper.

\section{References}

Aikhenvald, Alexandra Y. 2010. Imperatives and commands. Oxford: Oxford University Press.

Alapatov, Vladimir. 2001. Modern Japanese. In Victor S. Xrakovski (ed.), Typology of imperative constructions, 106-125. Munchen: Lincolm.

van der Auwera, Johan, \& Aguilar Cordoba, Alfonso Z. forthcoming. The history of mood and modality. In Johan van der Auwera and Jan Nuyts (eds.), The Oxford handbook of mood and modality. Oxford: Oxford University Press.

van der Auwera, Johan, Nina Dobrushina, \& Valentin Goussev. 2005. Imperativehortative systems. In Martin Haspelmath (ed.), The world atlas of language structures, 294-296. Oxford: Oxford University Press. 
van der Auwera, Johan, \& Ludo Lejeune. 2005. Imperative-hortative systems. In Martin Haspelmath (ed.), The Morphological Imperative. In Martin Haspelmath (ed.), The world atlas of language structures, 286-289. Oxford: Oxford University Press.

Bach, Kent. 1998. Standardization Revisited. In Asa Kasher (ed.), Pragmatics: Critical assesment. vol. IV:712-722. London: Routledge.

Bach, Kent, \& Robert M. Harnish. 1979. Linguistic communication and speech acts. Cambridge, Mass.: MIT Press.

Barker, Stephen. 2004. Renewing meaning : A speech-act theoretic approach. Oxford: Clarendon Press.

Barnes, Janet. 1979. Los Imperativos En Tuyuca. Artículos en lingüística y campos afines 6. 87-94.

Barnes, Janet. 1994. Tuyuca. In Peter Kahrel and René van den Berg (eds.), Typological studies in negation, 325-342. Amsterdam: John Benjamins.

Birjulin, Leonid A., \& Victor S. Xrakovski. 2001. Imperative sentences: theoretical problems. In Victor S. Xrakovski (ed.), Typology of imperative constructions, 3-50. Munchen: Lincolm.

Boeder, Winfried. 2010. Mood in modern Georgian. In Björn Rothstein and Rolf Thieroff (eds.), Mood in the languages of Europe, 603-633. Amsterdam: John Benjamins.

Bybee, Joan L., Revere D. Perkins, \& William Pagliuca. 1994. The evolution of grammar. Tense, aspect, and modality in the languages of the world. Chicago: University of Chicago Press.

Bystrov, Igor S., \& Nonna V. Stankevič. 2001. Imperative in Vietnamese. In Victor S. Xrakovski (ed.), Typology of imperative constructions, 461-474. Munchen: Lincolm.

Crnič, L., \& T. Trinh. 2009. Embedding imperatives in English. In A. Riester and T. Solstad (eds.), Proceedings of Sinn Und Bedeutung 13, 113-127. University of Stuttgart.

Davies, Eirlys. 1986. The English imperative. Beckenham: Croom Helm.

de Groot, Casper. 2014. Mood in Hungarian. In Björn Rothstein and Rolf Tieroff (eds.), Mood in the languages of Europe, 551-567. Amsterdam: John Benjamins.

De Haan, Ferdinand. 2011. Tense, aspect, and modality systems. In Jae Jung Song (ed.) The Oxford handbook of linguistic typology, 445-464. Oxford: Oxford University Press.

Đình-Hoà, Nguyễn. 1997. Vietnamese. Amsterdam: John Benjamins.

Dobronravin, Nikolaj A., \& Myrrah A. Smirnova. 2001. Imperative constructions in Hausa. In Victor S. Xrakovski (ed.), Typology of imperative constructions , 329-351. Munchen: Lincolm.

Dominicy, Marc, \& Nathalie Franken. 2002. Speech Acts and Relevance theory. In Daniel Vanderveken and Susumo Kubo (eds.) Essays in speech act theory, 263-283. Amsterdam: John Benjamins.

Du Feu, Veronica. 1996. Rapanui. New York: Routledge.

Dum-Tragut, Jasmine. 2009. Armenian. Amsterdam: John Benjamins.

Elliott, Jennifer R. 2000. Realis and irrealis: forms and concepts of the grammaticalisation of reality. Linguistic Typology 4(1). 55-90.

Fiengo, Robert. 2007. Asking questions. Using meaningful structures to imply ignorance. Oxford: Oxford University Press.

Golovko, Evgenij V. 2001. Imperative in Aleut. In Victor S. Xrakovski (ed.), Typology of imperative constructions, 300-314. Munchen: Lincolm.

Grice, Herbert P. 2001. Aspects of reason. Oxford: Clarendon Press.

Groenendijk, Jeroen, \& M. Stokhof. 1989. Type-shifting rules and the semantics of 
interrogatives. In Gennaro Chierchia, Barbara H. Partee, \& Raymond Turner (eds.) Properties, types and meaning. Volume 2: Semantic issues, 21-68. Dordrecht: Kluwer.

Gruzdeva, Ekaterina Y. 2001. Imperative Sentences in Nivkh. In Victor S. Xrakovski (ed.), Typology of imperative constructions, 59-77. Munchen: Lincolm.

Gusev, Vasilii J. 2013. Tipologija imperativa. Moscou: Iaziki Slavanskoj Kulturi. Hamblin, Charles. 1987. Imperatives. Oxford: Blackwell.

Han, Chung-Hye. 2000. The Structure and interpretation of imperatives. Mood and force in universal grammar. New York: Garland.

Haspelmath, Martin. 2010. comparative concepts and descriptive categories in crosslinguistic studies. Language 86(3). 663-87.

Heath, Jeffrey. 1984. Functional grammar of Nunggubuyu. Canberra: Australian Institute of Aboriginal Studies.

Huddleston, Rodney, and Geoffrey K. Pullum. 2002. The Cambridge grammar of the English language. Cambridge: Cambridge University Press.

Jary, Mark. 2010. Assertion. London: Palgrave.

Jary, Mark. 2011. Assertion, relevance and the declarative mood. In V. Escandell-Vidal, V. Leonetti, \& A. Ahern (eds.), Procedural meaning: Problems and perspectives, 267292. Emerald: Bingley.

Jary, Mark, \& Mikhail Kissine. in press. Imperatives as (non-)modals. In Joanna Balszczak, Dorota Klimek-Jankowska, and Krzysztof Migdalski (eds.) Crosslinguistic approaches to tense, aspect and mood. Chicago: Chicago Univerisyt Press.

Jary, Mark, \& Mikhail Kissine. 2014. Imperatives. Cambridge: Cambridge University Press.

Kaufmann, Magdalena. 2012. Interpreting imperatives. Dordrecht: Springer.

Kenesei, István, Robert Michael Vago, \& Anna Fenyvesi. 1998. Hungarian. London: Routledge.

Kissine, Mikhail. 2009. Illocutionary forces and what is said. Mind and Language 24(1). 122-138.

Kissine, Mikhail. 2012. Sentences, utterances, and speech acts. In Keith Allan and Katarzyna M. Jaszczolt (eds.), Cambridge handbook of pragmatics, 169-190. Cambridge: Cambridge University Press.

Kissine, Mikhail. 2013. From utterances to speech acts. Cambridge: Cambridge University Press.

Kozintseva, Natalia A. 2001. Imperative sentences in Armenian. In Victor S. Xrakovski (ed.) Typology of imperative constructions, 245-267. Munchen: Lincolm.

Kripke, Saul A. 1980. Naming and necessity. Cambridge, Mass.: Harvard University Press.

Levinson, Stephen C. 1983. Pragmatics. Cambridge: Cambridge University Press.

Levinson, Stephen C. 2012. Interrogative intimations: On a possible social economics of interrogatives. In Jan P. de Ruiter (ed.) Questions: Formal, functional and interactional perspectives, 11-32, Cambridge: Cambridge University Press.

Maier, Emar. 2010. Quoted imperatives. In Martin Prinzhorn, Viola Schmitt, and Sarah Zobel (eds.), Proceedings of Sinn Und Bedeutung 14, 289-304. Vienna.

Mastop, Rosja. 2005. What can you do? Imperative mood in semantic theory. Amsterdam: Amsterdam University PhD Dissertation.

Mauri, Caterina, \& Andrea Sansò. 2011. How directive constructions emerge: grammaticalization, constructionalization, cooptation. Journal of Pragmatics 43(14). 3489-3521.

Mauri, Caterina, \& Andrea Sansò. 2012. The Reality status of directives and its coding 
across languages. Language Sciences 34(2). 147-170.

Morgan, Jerry L. 1978. Two types of convention in indirect speech acts. In Peter Cole (ed.) Syntax and Semantics. Vol. 9: Pragmatics, 261-280. New York: Academic Press.

Nasilov, Dmitij M., Xoršid F. Isxakova, Šaxrijor S. Safarov, \& Irina A. Nevskaja. 2001. Imperative sentences in Turkic Languages. In Victor S. Xrakovski (ed.), Typology of imperative constructions, 181-220. Munchen: Lincolm.

Ogloblin, Alexander K. 2001. Imperative sentences in Javanese. In Victor S. Xrakovski (ed.), Typology of imperative constructions, 221-242. Munchen: Lincolm.

Popjes, Jack, \& Jo Popjes. 1986. Canela-Krahô. In Desmond C. Derbyshire and Geoffrey K. Pullum (eds.), Handbook of Amazonian languages, Volume 1, 128-199. Berlin: Mouton de Gruyter.

Portner, Paul. 2007. Imperatives and modals. Natural Language Semantics 15(4). 35183.

Recanati, François. 1987. Meaning and force : The pragmatics of performative utterances. Cambridge: Cambridge University Press.

Ruytenbeek, Nicolas. in press. A critical review of experimental research on indirect requests comprehension. In Ilse Depraetere \& Raphael Salkie (eds.), Drawing a line: Perspectives on the semantics-pragmatics interface. Dordrecht: Springer.

Sadock, Jerrold M. 1974. Toward a linguistic theory of speech acts. New York: Academic Press.

Sadock, Jerrold M., \& Arnold M. Zwicky. 1985. Speech act distinctions in syntax. In Language typology and syntactic description. Volume I: clause structure, edited by Timothy Shopen, 155-196. Cambridge: Cambridge University Press.

Searle, John R. 1975a. A taxonomy of illocutionary acts. In Keith Gunderson (ed.), Language, mind and knowledge, 344-369. Minneapolis: University of Minnesota Press.

Searle, John R. 1975b. Indirect speech acts. In Peter Cole and Jerry L. Morgan (eds.), Syntax and Semantics 3: Speech Acts, 59-82. New York: Academic Press.

Searle, John R., \& Daniel Vanderveken. 1985. Foundations of illocutionary logic. Cambridge: Cambridge University Press.

Siemund, Peter. 2001. Interrogative constructions. In Martin Haspelmath, Ekkehard König, Wulf Oesterreicher, and Wolfgang Raible (eds.), Language typology and language universals, 1010-1027. Berlin: Mouton de Gruyter.

Sperber, Dan, \& Deirdre Wilson. 1995. Relevance: Communication and cognition. Second edition. Oxford: Blackwell.

Stefanowitsch, Anatol. 2003. A construction-based approach to indirect speech acts. In Klaus-Uwe Panther and Linda L. Thornburg (eds.), Metonymy and pragmatic inferencing, 105-126. Amsterdam: John Benjamins.

Van de Velde, Mark. 2009. Agreement as a grammatical criterion for proper name status in Kirundi. Onoma 44: 219-241.

Van Olmen, Daniël. 2011. The imperative in English and Dutch: A functional analysis in comparable and parallel corpora. Antwerpen: Antwerpen University: PhD dissertation.

Verstraete, Jean-Christophe. 2005. The semantics and pragmatics of composite mood marking: Non-Pama-Nyungan languages of Northern Australia. Linguistic Typology 9. 223-268.

Wilson, Deirdre, \& Dan Sperber. 1988. Mood and the analysis of non-declarative sentences. In Jonathan Dancy, Julius M. Moravcsik, \& Christopher C.W. Taylor 
(eds.), Human agency, language, duty and value. Philosophical essays in honour of J.O. Urmson, 77-101. Stanford: Stanford University Press.

Zanuttini, Raffaella, Miok Pak, \& Paul Portner. 2012. A syntactic analysis of interpretive restrictions on imperative, promissive, and exhortative subjects. Natural Language \& Linguistic Theory 30(4). 1231-1274. 